\title{
Chosen Solutions to the Engineering Challenges of the National Spherical Torus Experiment (NSTX) Magnets
}

\author{
Philip Heitzenroeder, James Chrzanowski, Charles Neumeyer, Horng-Ming Fan and the NSTX Team* \\ Princeton Plasma Physics Laboratory, PO Box 451, Princeton, NJ 08543 USA
}

\begin{abstract}
NSTX is one of the largest of a new class of magnetic plasma research devices known as spherical toroids (STs). The plasma in a ST is characterized by its almost spherical shape with a slender cylindrical region through its vertical axis. The so-called "center stack" is located in this region. It contains magnetic windings for confining the plasma, induce the plasma current, and shape the plasma. This paper will describe the engineering challenges of designing the center stack magnets to meet their operational requirements within this constrained space.
\end{abstract}

Index Terms—Spherical toroids; magnets; magnet engineering.

\section{INTRODUCTION}

NSTX achieved its first plasma in February, 1999, and began experimental operations in August, 1999. A photograph of NSTX during final construction is shown in Figure 1. It was constructed by the Princeton Plasma Physics Laboratory in collaboration with the Oak Ridge

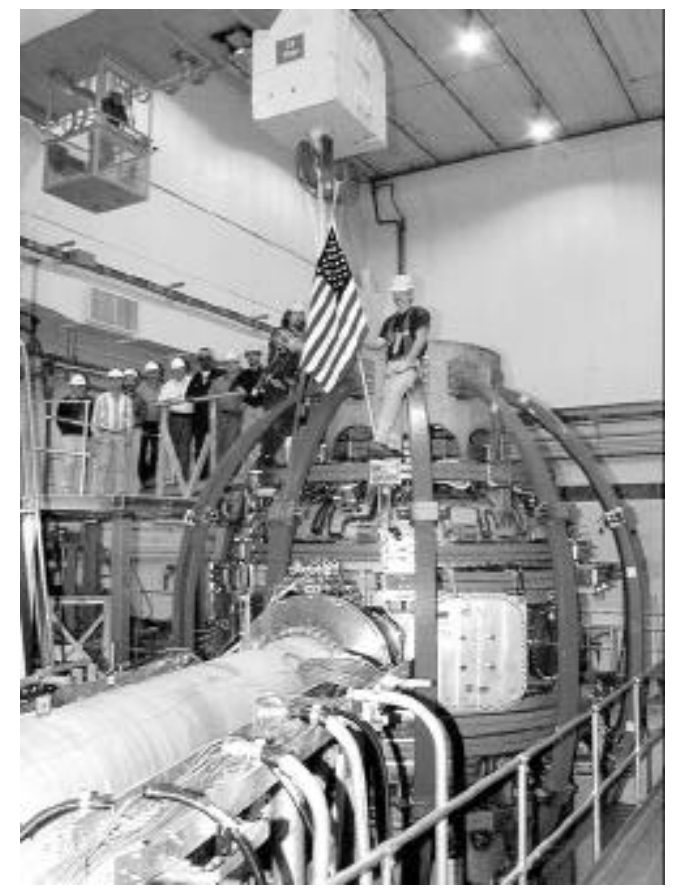

Figure 1. NSTX During Construction in January, 1999

*This work was supported by the US Department of Energy contract no. DE-AC02-76-CHO3073.
National Laboratory, Columbia University, and the University of Washington at Seattle.

Spherical toroids are attractive because of their ability to confine a much higher plasma pressure for a given magnetic field compared to more traditional magnetic confinement devices such as the tokamak. Fusion power is proportional to the square of the magnetic pressure; consequently, STs may permit smaller, more economical fusion reactors to be developed. The major design parameters of NSTX are given in Table 1.

\section{TABLE 1. MAJOR PARAMETERS OF NSTX}

\begin{tabular}{|l|l|}
\hline $\begin{array}{l}\text { Plasma Major Radius, } \mathrm{R}_{0} \\
(\mathrm{~m})\end{array}$ & 0.85 \\
\hline Aspect Ratio, $\mathrm{R}_{0} / \mathrm{a}$ & 1.27 \\
\hline $\begin{array}{l}\text { Maximum Toroidal Field at } \\
\mathrm{R}_{0}(\mathrm{kG})\end{array}$ & 6.0 \\
\hline Plasma Current (MA) & 1.0 \\
\hline Plasma Flat Top Time (s) & $0.5 \quad$ (inductive operation) \\
& $5.0 \begin{array}{l}\text { (driven current } \\
\text { operation) }\end{array}$ \\
\hline
\end{tabular}

\section{Design OVERVIEW}

A cross section of NSTX is shown in Figure 2. The center stack, shown in Figure 3, is the most complex and critical component of NSTX. It is designed as a module so it can be easily removed for future upgrades or maintenance. It consists of the following elements:

- The TF inner leg bundle is the innermost element of the center stack. It contains (36) bars which comprise the central legs of the toroidal field (TF) system which generates the plasma confinement field. Parameters for the TF system are listed in Table 2.

- Surrounding the TF bundle is the Ohmic Heating $(\mathrm{OH})$ solenoid. This solenoid generates the loop voltage to initiate, and flux swing to drive the plasma current. The $\mathrm{OH}$ is wound on a flanged 


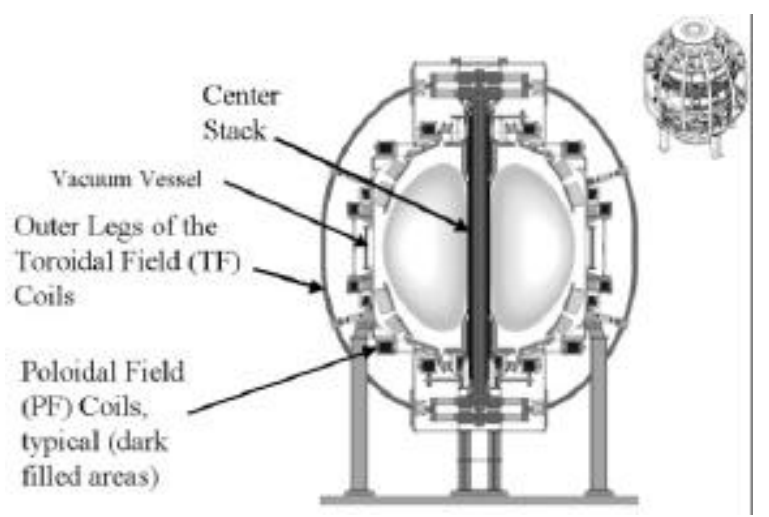

Figure 2. Section View of NSTX Identifying Major Components

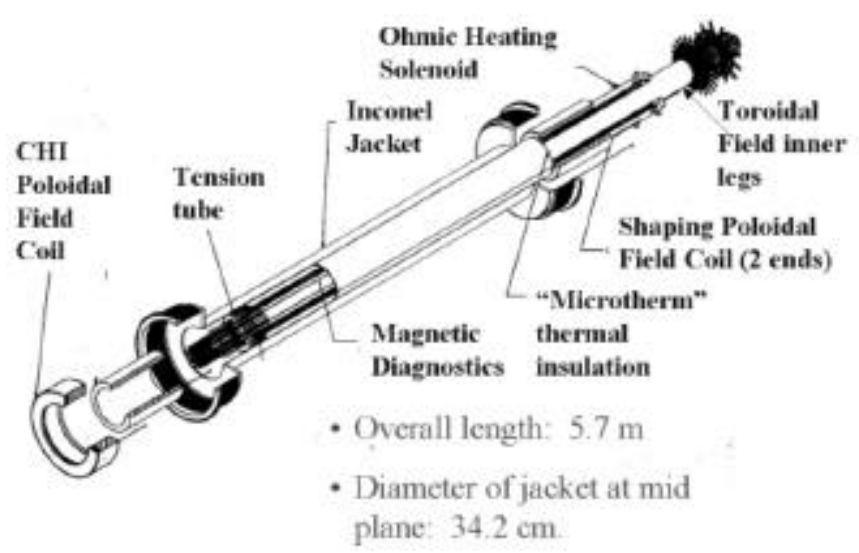

Figure 3. NSTX Center Stack

$3 \mathrm{~mm}$ thick stainless steel tension tube which supports the $\mathrm{OH}$ coil while still permiting axial thermal expansion. The tension tube also supports the shaping field coils which are described below. The 962 turn winding is arranged in 4 layers, wound 2 in hand to provide 8 parallel cooling paths to minimize thermal gradients (and shear stresses) during cool-down. Parameters of the $\mathrm{OH}$ system are listed in Table 3.

- Shaping field (PF1a) coils are located concentric to the solenoid near both ends. These coils provide the field shaping necessary to form NSTX's plasma geometry.

- A single coil (PF1b) is located on the lower end of the CS assembly. This coil forms the magnetic geometry required for a Coaxial Helicity Injection (CHI) experiment

- Magnetic diagnostics, including flux loops, and Rogowski coils are installed on the surface of the $\mathrm{OH}$ coil.
- A thermal insulation jacket, supplied by Microtherm, Inc, of Maryville, Tn. over-wraps the $\mathrm{CS}, \mathrm{OH}, \mathrm{PF}$, and magnetic diagnostics to protect them from heat emanating inwards from the center stack casing. The casing can reach temperatures in the range of $600 \mathrm{C}$ during operation and bakeout.

- The center stack casing made of $4 \mathrm{~mm}$ Inconel, surrounds the assembly and forms the inner wall of the vacuum vessel.

- The center stack casing surface is protected by graphite and carbon-carbon tiles. These are necessary to protect the casing and to minimize sputtering of metallic impurities during operation.

- Connecting to the TF bundle through flexible laminated copper straps are the outer legs of the TF coils. Each outer coil contains three turns of copper which are water cooled by tubes are soldered into grooves in each turn.. The turns are bonded together with B-stage epoxy/glass. Lateral loads are reacted through the umbrella structure; outwards $\mathrm{I}_{\mathrm{TF}} \quad \mathrm{X} \mathrm{B}_{\mathrm{TF}}$ loads are reacted by struts attached to the vacuum vessel.

- The external PF coils 2, 3, 4, and 5 are of conventional water cooled hollow copper construction. They are up-down symmetric. Three sets are from the former S-1 Spheromak; one set was newly constructed. The parameters of the PF coils are given in Table 3.

\section{TABLE 1. NSTX TF COIL PARAMETERS}

\begin{tabular}{|l|l|}
\hline Parameter & Value \\
\hline Number of coils & 12 \\
\hline Turns per coil & 3 \\
\hline $\begin{array}{l}\text { Toroidal field in Tesla at } \\
\mathrm{R}_{0}=0.854 \mathrm{~m}\end{array}$ & 0.6 \\
\hline Current per turn, kA & 71.2 \\
\hline $\begin{array}{l}\text { Max. terminal to terminal } \\
\text { voltage }\end{array}$ & 1000 \\
\hline Turn to turn insulation & $\begin{array}{l}\text { (3) layers 0.18mm CTD- } \\
112 \mathrm{P} \text { B-stage epoxy glass }\end{array}$ \\
\hline $\begin{array}{l}\text { Maximum insulation stress, } \\
\text { v/mil }\end{array}$ & 15.8 \\
\hline $\begin{array}{l}\text { Equivalent square wave } \\
\text { time, } \mathrm{s}\end{array}$ & $\begin{array}{l}1.3 / 5.0 \text { (Inductive / driven } \\
\text { plasma current operation) }\end{array}$ \\
\hline Time between pulses, $\mathrm{s}$ & 300 \\
\hline $\begin{array}{l}\text { Max. current density, } \\
\text { kA / cm }\end{array}$ & $\begin{array}{l}10.5 \text { (inner legs) } \\
1.9 \text { (outer legs) }\end{array}$ \\
\hline
\end{tabular}


TABLE 2. NSTX OH COIL PARAMETERS

\begin{tabular}{|l|l|}
\hline Flux (double swing), V-s & 0.6 \\
\hline Initiation loop voltage, v/t & 5 \\
\hline Current per turn & $24 \mathrm{kA}$ \\
\hline Turns & 962 \\
\hline Winding arrangement & 4 layers, wound 2 in hand. \\
\hline $\begin{array}{l}\text { Equivalent square wave } \\
\text { time, s }\end{array}$ & 0.525 \\
\hline $\begin{array}{l}\text { Maximum copper temp., }{ }^{0} \mathrm{C} ; \\
\text { ( } 10^{0} \mathrm{C} \text { inlet temp.) }\end{array}$ & 94.5 \\
\hline $\begin{array}{l}\text { Insulation voltage stress, } \\
\text { v/mil }\end{array}$ & 71.2 \\
\hline $\begin{array}{l}\text { Turn to turn insulation } \\
\text { details }\end{array}$ & $\begin{array}{l}(1) \text { layer 0.18mm CTD- } \\
112 \mathrm{P} \text { B-stage epoxy glass } \\
\text { interleaved with 0.05 mm } \\
\text { polyimide half lapped plus } \\
(1) \text { layer CTD-112P half } \\
\text { lapped. }\end{array}$ \\
\hline Peak voltage & \begin{tabular}{l} 
6077 \\
\hline
\end{tabular}
\end{tabular}

Table 3 NSTX External PF Coils

\begin{tabular}{|l|l|l|l|}
\hline Coil & I (kA) & ESW (s) & N(turns) \\
\hline PF 2 & 20 & 5.0 & 28 \\
\hline PF3 & 20 & 5.0 & 30 \\
\hline PF4 & 20 & 5.0 & 17 \\
\hline PF5 & 20 & 5.0 & 24 \\
\hline
\end{tabular}

\section{ENGINEERING CHALLENGES OF THE NSTX MAGNETS}

The performance increases in STs which derive from lower aspect ratio, $\mathrm{R}$ (major plasma ratio) / a (minor plasma ratio) makes the cylindrical space available for the center stack extremely valuable. Consequently, compact, high performance designs are required for all of the center stack components. The coils must be designed with relatively high current densities, and consequently relatively high temperature rises, thermal expansions, and stresses. Challenging, but attainable assembly clearances had to be set to assure that the parts could be manufactured, and at reasonable costs. This was one of the major challenges in designing NSTX. The slenderness of the center stack ( mid plane diameter $34 \mathrm{~cm}$; length $5.6 \mathrm{~m}$ ) of the center stack complicated the setting of tolerances. Straightness and circularity tolerances both had to be carefully chosen. The tight coaxial placement of the TF center stack, $\mathrm{OH}$ solenoid, and PF $1 \mathrm{a}$ and $1 \mathrm{~b}$ coils generate fields at their ends which cross over the TF current and create a torque in the TF bundle. Consequently an insulating material had to be identified which would develop adequate shear strength at operating temperature, since the strength of epoxies change considerably with temperature. Thermal expansions had to be accommodated in the design of the structures and electrical connections. The TF center stack length, for example, increases by $\sim 9 \mathrm{~mm}$ during a pulse.

\section{Design Solutions Chosen to AdDRESS THE ENGINEERING CHALLENGES}

Several basic decisions made early in the design process guided the engineering details of the center stack:

- The coils should structurally decoupled as much as possible. This decision was made to minimize shear stresses between coils, to provide simple and easily analyzed load paths, to permit parallel fabrication of the $\mathrm{TF}, \mathrm{OH}$, and $\mathrm{PF}$ center stack coils, and to improve failure recovery.

- The TF center stack legs should be shear bonded by the turn to turn electrical insulation. This decision was primarily based on the desire to avoid more complex methods such as shear keys. It was also decided to provide torque reaction structures to reduce the shear stress level.

- The current densities for the center stack $T F$ and $\mathrm{OH}$ coils should be such that the maximum temperature of the coils would be just below $100 \mathrm{C}$. We judged this temperature to be the most reasonable balance between the need for compactness and the desire for cost effective designs. With the avoidance of boiling, a straightforward water cooling system could be used and the possible candidates for the epoxy/glass insulation system would be broader.

- Structures and bus connections must be designed to permit free thermal expansions to avoid excessive thermal stresses. This led to the incorporation of flexible electrical connectors and the spline connection in the torque reaction structure.

\section{TF Bundle Design Details.}

Figure 4 shows the geometry developed for the TF center bundle.

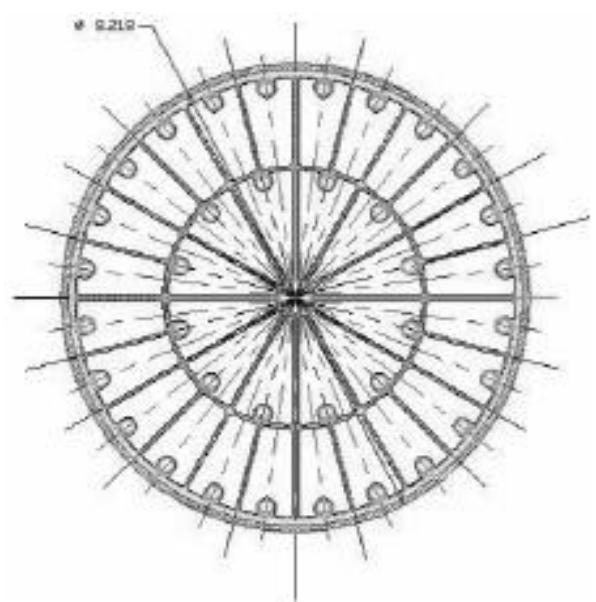

FIGURE 4. TF CENTER BUNDLE CONDUCTOR GEOMETRY 
The two-layer design efficiently utilizes the available space. A notable feature of this geometry is its quadrant symmetry. As shown in Figure 5, this permitted the quadrants to be press cured using precision molds. The four quadrants were then bonded together to form the TF center bundle in a second press curing operation. The $\mathrm{TF}$ and $\mathrm{OH}$ manufacturer was Everson Electric of Bethlehem, Pa.. This two step manufacturing technique was successful in achieving the tolerances required for assembly with the clearances specified in Figure 6.

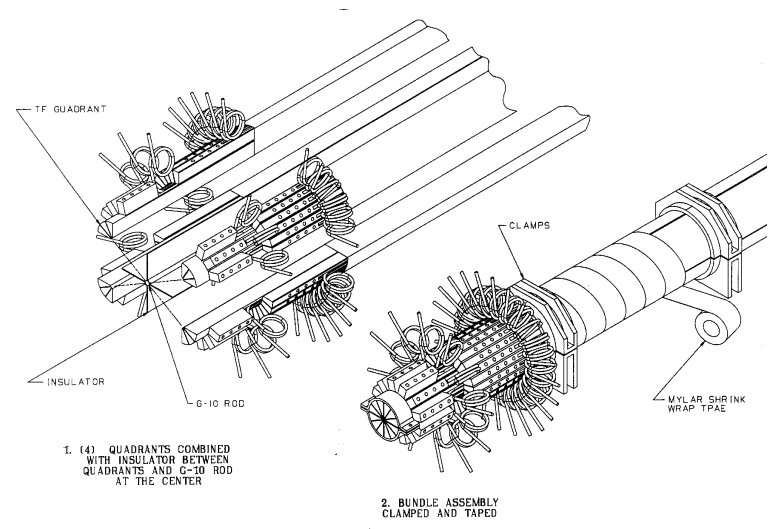

FIGURE 5. TF CENTER BUNDLE ASSEMBLY FROM QUADRANTS

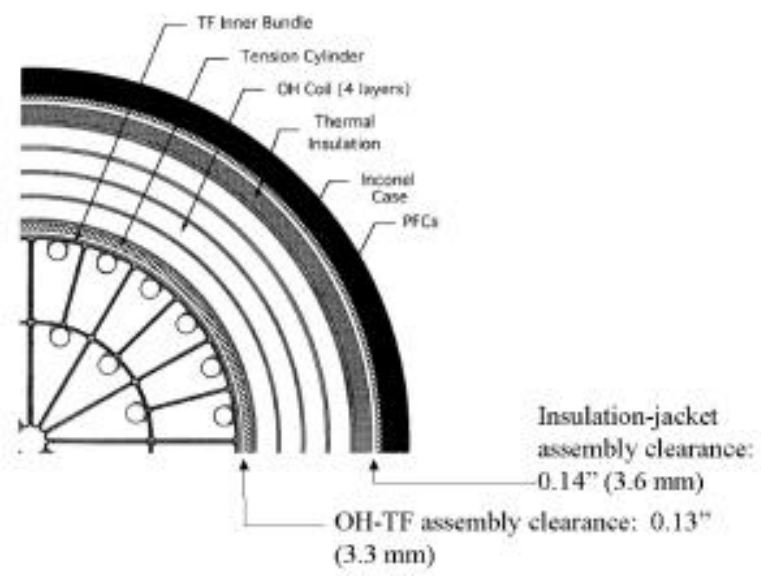

FIGURE 6. CENTER STACK ASSEMBLY CLEARANCES

The two layer geometry was also chosen because of its compatibility with a two-tier bolted joint design. The joints consist of copper "flags" which connect to the outer legs of the TF coil through laminated flexible copper straps. Long A286 bolts provide $13.8 \mathrm{MPa}$ (2ksi) pressure at the joint. The contact surfaces are silver plated to reduce resistance. Transient thermal analyses were performed to verify sufficient joint pressure throughout the pulse. The flags are supported by a hub structure shown in Figure 7. G-10 wedges are driven between the flags and G-10 shims are installed in the vertical direction between the flags and hubs. The shims and wedges lock the flags and hub together. The net lateral and vertical loads on the flags from the $\mathrm{TF}$

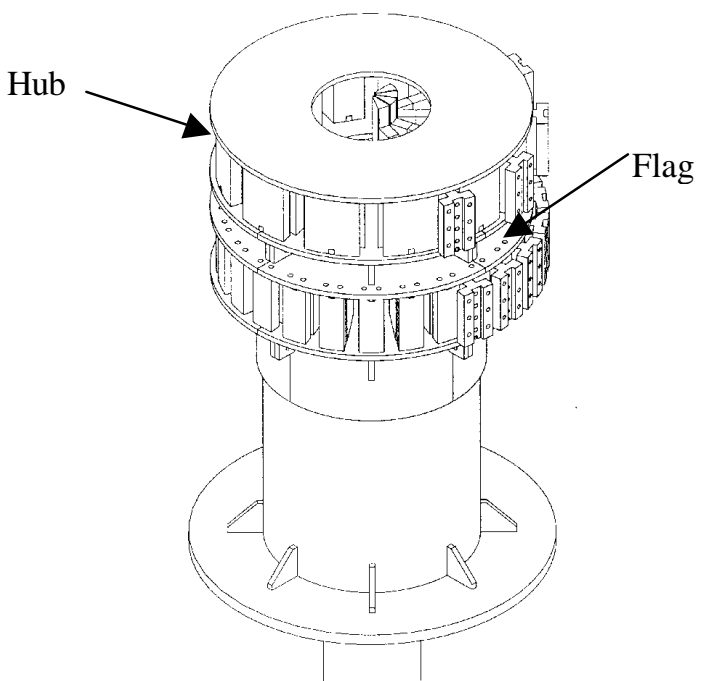

FIGURE 7. TF BOLTED JOINT AND HUB SUPPORT STRUCTURE

current interacting with crossing vertical and toroidal fields are reacted by the flag bolts in shear; these bolts are body bound at the joint. Figure 8 is a photograph of the top of NSTX showing the flexible connectors between the center stack and TF coil outer legs.

The torque on the TF center bundle from the interaction of the $\mathrm{OH}$ and $\mathrm{PF}$ fields are also reacted through the hubs. Figure 9 shows the elements which make up the torque reaction structure. Stainless steel collars bonded to the TF bundle just beyond the ends of the $\mathrm{OH}$ coil transfers the torsional load through a bolted connection to the hub. The hub transfers the torsion to the umbrella structure through bolted connection to the umbrella structure on the bottom half of the machine and thorough a spline on the upper half. The umbrella structure reacts the torque to the vacuum vessel. The upper spline permits the $\sim 9 \mathrm{~mm}$ thermal growth of the center stack. The center stack is vertically supported

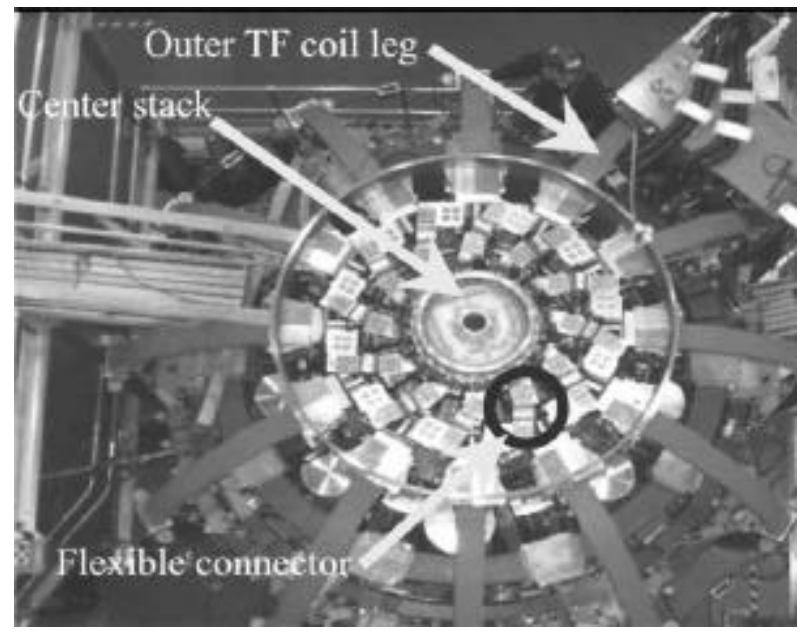

FIGURE 8. TOP VIEW OF NSTX SHOWING FLEXIBLE STRAP CONNECTORS OF TF SYSTEM 


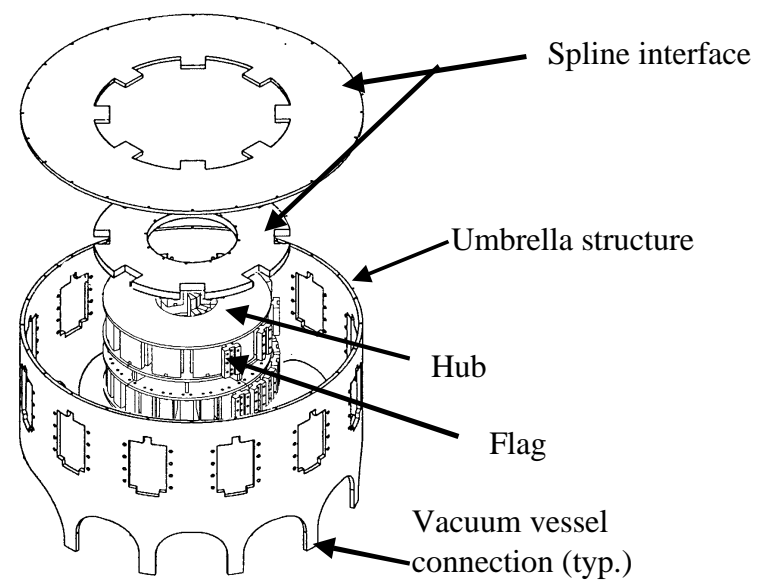

FIGURE 9. TORQUE REACTION STRUCTURE

on a bottom pedestal.

\section{OH COIL Design DetaILs}

A cross section of the $\mathrm{OH}$ coil is shown in Figure 10. A feature of the design is the use of the tension tube as both the $\mathrm{OH}$ winding form and supporting structure for the $\mathrm{OH}$ solenoid and the shaping PF coils located at its ends. The machined inner diameter of the tension tube, therefore, defined one of the critical clearances of the solenoid. The other critical function of the tension tube is to serve as the supporting and locating structure of the solenoid. The tension tube is supported at the lower end from a pedestal to the experimental area floor. A Belleville washer assembly provides an axial preload and upwards load reaction path to the solenoid but allows axial thermal growth. Although the net axial loads on the solenoid due to the interaction between the $\mathrm{OH}$ and $\mathrm{CHI}$ PF coil are interlocked to be only downwards, the tension tube provides a load path in the

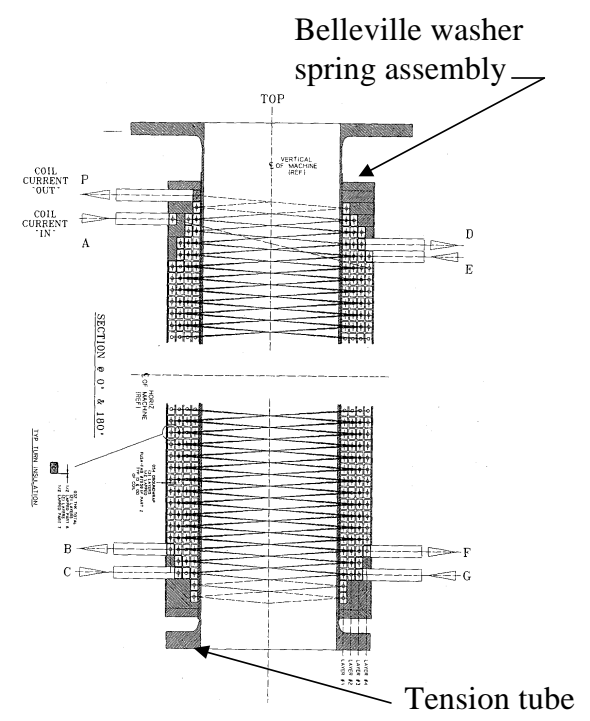

FIGURE 10. OH SOLENOID CROSS SECTION case of interlock failure. Figure 11 shows the support of the PF1A coils from the tension tube.

The $\mathrm{OH}$ coil was wound with 4 layers, two in hand to: (1) to shorten the flow path length to avoid the necessity for high water flow velocities and (2) to permit the coil to be wound with joints only between layers with the commercially available lengths.

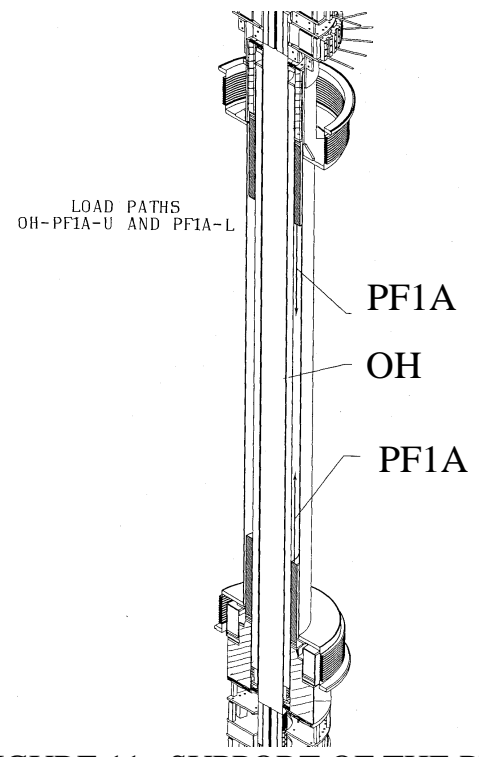

FIGURE 11. SUPPORT OF THE PF 1A (SHAPING FIELD) COILS BY THE OH TENSION TUBE.

Figure 12 shows the details of a joint developed for the layer to layer joints in the $\mathrm{OH}$ coil. This joint avoids annealing of the CDA-10700 conductor and maintains the strength necessary. The $\mathrm{OH}$ coil copper is stressed to the $142 \mathrm{Mpa}$ (20.5 ksi) during operation. The overlapped surfaces are pre-tinned with $96 \%$ tin/4\% silver solder. The ends of the conductors are TIG tack brazed with a short (7-10 s) braze time. Tests indicate a joint static strength of $235 \mathrm{MPa}$ (34 $\mathrm{ksi}$ ) and a fatigue life of $\sim 400,000$ cycles with a stress range of $138 \mathrm{Mpa}(20 \mathrm{ksi})$.

\section{STRESS ANALYSIS SUMMARY}

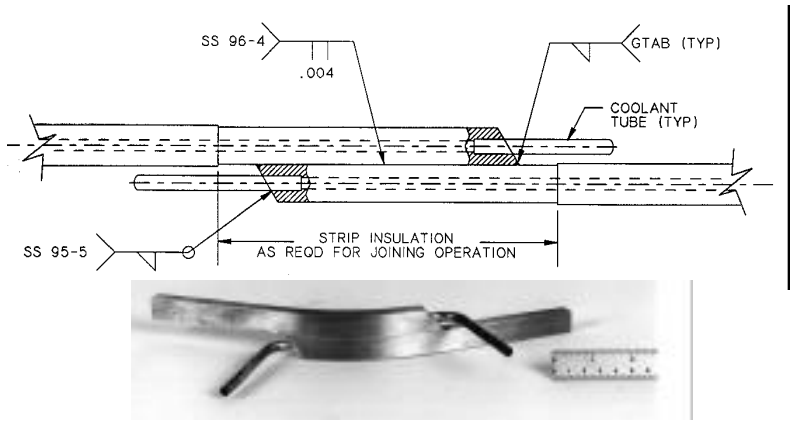

FIGURE 12. OH COIL LAYER TO LAYER JOINT 
Coupled magnetic / structural analyses were performed using ANSYS Rev. 5.3. The calculated TF center stack bundle copper Von Mises stress is $75.4 \mathrm{MPa}$ (10.9 ksi). The allowable stress for the CDA 10700 copper TF inner leg copper, based on $2 / 3$ yield, is $145.3 \mathrm{MPa}$ (21 ksi). The calculated OH coil copper Von Mises stress is $141.9 \mathrm{MPa}$ (20.5 ksi). The allowable for the $\mathrm{OH}$ conductor is $166 \mathrm{MPa}$ (24 ksi). The fatigue life of the $\mathrm{OH}$ coil was also evaluated, based on a criteria that the range stress allowable must be less than 0.5 times the fatigue stress at life or the stress at 20 times life. These results are shown in Figure 13.

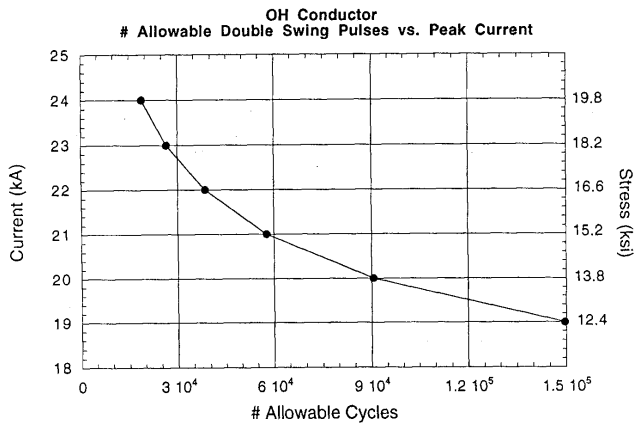

FIGURE 13. OH COIL FATIGUE LIFE AT VARIOUS OPERATING LEVELS

\section{INSULATION SHEAR}

Shear stresses in the TF and $\mathrm{OH}$ coils were evaluated using a series of ANSYS models. The requirements for the TF are for the insulation to have a shear allowable $>13.7 \mathrm{MPa}$ (2ksi) at $60{ }^{\circ} \mathrm{C}$ (the temperature at peak shear), and for the $\mathrm{PF}$, a shear allowable > $6.8 \mathrm{MPa}(1 \mathrm{ksi})$ at $100{ }^{\circ} \mathrm{C}$ (the peak shear is during the cool-down, when the coil is at maximum temperature). Tests on candidate materials were performed both by Cryogenics Materials, Inc. of Boulder, Co, and at PPPL. Based on these tests, CTD-112P TGDM epoxy/ S-2 glass B-stage, which was developed for ITER, was selected. This epoxy formulation was developed by Composite Technology Development, Inc. of Boulder, Co. The B-stage material is supplied by Insulating Materials, Inc. of Rochester, NY. Prior to application of the insulation, the conductors for both the $\mathrm{OH}$ and TF coils are grit blasted, solvent wiped, and primed with Ciba-Geigy DZ-80 primer. The TF insulation consists of (3) layers of the $0.18 \mathrm{~mm}$ (0.007”) thick b-stage tape, half lapped. This material was tested for $10^{6}$ cycles with an shear stress of $16.6 \mathrm{Mpa}$ (2.4 ksi ) and a lateral (compressive) load $4.2 \mathrm{MPa}$ (600 psi) at $60^{\circ} \mathrm{C}$. The PF insulation has a much greater voltage stress (71.8 vs. $15.2 \mathrm{v} / \mathrm{mil})$. Consequently, the $\mathrm{PF}$ insulation consists of one layer half lapped of $0.18 \mathrm{~mm}$ B-stage tape interleaved with $0.05 \mathrm{~mm}$ polyimide tape (treated for bonding) over wrapped with one layer of $0.18 \mathrm{~mm} \mathrm{~B}$-stage tape. This combination was tested for $10^{6}$ cycles at a shear stress of $6.8 \mathrm{MPa}(1 \mathrm{ksi})$ and a lateral (compressive) load of 4.2 $\mathrm{MPa}(600 \mathrm{psi})$ at $100^{\circ} \mathrm{C}$.

\section{SUMMARY}

The need for a low aspect ratio in NSTX and STs in general requires compact, high performance coil and structure designs. The coils must have relatively high current densities, which result in relatively high stresses and temperatures. The interactions between the TF inner legs and PF center stack coils results in a torque which has to be reacted by the TF legs and structure. The design choices made by NSTX include structurally independent coils, "slide together" assembly of the center stack, the use of flexible electrical connectors, and structures which can accommodate the thermal growth. Manufacturing clearances had to be set which were challenging but achievable. The CTD-112P epoxy/glass insulation chosen demonstrates adequate shear strength at NSTX's operating temperatures. The TIG braze/soldered joint developed for the $\mathrm{OH}$ coil avoids annealing and exhibits good static and fatigue strength. Integrated operational tests recently performed, although not yet at full power levels, have been successful. Experimental operation of NSTX has begun.

\section{ACKNOWLEDGEMENTS}

The authors thank the entire NSTX team for their contributions to this work. We are particularly indebted to Mr. John Citrolo and Mr. John Spitzer for their critical contributions to the engineering of the NSTX magnets and Mr. Lew Morris and Mr. Joeseph Rushinski for their many contributions to the design concepts and outstanding preparation of the computer aided design drawings.

\section{REFERENCES}

[1] Chrzanowski, James H. "National Spherical Torus Experiment Center Stack Research and Development Final Report"; Report No. 13-970430-JHC; April, 1997.

[2] Reed, Richard P., Cryogenics Materials, Inc. "NSTX Insulation Test Program Final Report”; March 17, 1997.

[3] Neumeyer, C. et. Al; "Engineering Overview of the National Spherical Torus Experiment (NSTX)"; IEEE /NPSS $17^{\text {th }}$ Symposium on Fusion Engineering, 1997.

[4] Citrolo, John C. "Center Stack Engineering “; NSTX February, 1997 Review. 